discuss this in his paper, is the selection of criteria for measurement. Traditionally body-weight gain and food conversion efficiency ratio have been employed as criteria in animal studies. Indeed these are eminently suitable criteria in the field of animal husbandry or at least in that portion of it concerned with meat production. But in human nutrition, we tend to look toward biochemical alterations with the hope that they may prove to be more sensitive criteria. Frequently 'tissue saturation' as measured by the 'load test' has been considered a suitable measure of nutritional status.

These three types of measurement do not necessarily give the same answer. This may be illustrated by some data we have accumulated on vitamin $\mathrm{B}_{6}$ in the rat. Some years ago we were interested in factors affecting tissue levels of the vitamin. We noted that, when pyridoxine hydrochloride was administered by daily subcutaneous injection to rats otherwise deprived of the vitamin, maximal liver vitamin $B_{6}$ concentrations were obtained at a dosage of $15^{-25} \mu \mathrm{g} /$ day; body-weight gain was still increasing at $25 \mu \mathrm{g} /$ day. Recently we have carried out a similar type of study, this time comparing blood transaminase activities and body-weight gain. We obtained a maximal body-weight response with about $40 \mu \mathrm{g}$ pyridoxine hydrochloride/day, but transaminase activity was still increasing at the $80 \mu \mathrm{g}$ level. One wonders then which criteria should be used in studying interrelationships--ability to store or retain the nutrient (seen here at $20-25 \mu \mathrm{g} /$ day), ability to increase body-weight ( $40 \mu \mathrm{g} /$ day), or maximal activity of an enzyme dependent upon the nutrient (in excess of $80 \mu \mathrm{g} /$ day). One might, and should, also consider the use of histological criteria.

The other problem we face is obvious-what should we study. With more than forty dietary constituents now established as being utilized by one species or another, the number of combinations that might be studied is virtually infinite.

It has frequently been said that the science of nutrition is in its infancy. In the area of nutrient interrelationships I am sure that we must agree this is true. But from the programme of this Symposium, I am sure that we will also agree that it is rapidly coming of age.

\title{
REFERENCES
}

Blaxter, K. L. (1964). Proc. Nutr. Soc. 23, 3.

Miller, D. S. \& Payne, P. R. (1964). Proc. Nutr. Soc. 23, 11.

\section{Dietary factors affecting vitamin requirements}

\section{By J. A. Campbel.*, Division of Food Technology and Nutrition, Faculty of Agricultural Sciences, American University of Beirut, Beirut, Lebanon}

Vitamin requirements are influenced by many factors, one of which is the content or proportion of other nutrients in the diet. This is probably to be expected since vitamins are directly involved in the metabolism of these nutrients. A glance at the literature indicates that studies have been made on the effect of most nutrients on

\footnotetext{
*Permanent address: Food and Drug Directorate, Department of National Health and Welfare, Ottawa, Canada.
} 
vitamin requirements. Selection of interrelationships to be discussed here was based primarily on recent work on some of those factors which have been of most interest to us and which illustrate some of the problems involved. Many other examples, of course, could have been chosen.

\section{Protein-nicotinic acid}

Proteins and their constituent amino acids have many effects on the metabolism of different vitamins. It has been known for some time that in man and animals tryptophan can substitute for nicotinic acid and will produce increased excretion of $\mathrm{N}^{\prime}$ methylnicotinamide. Gopalan \& Srikantia ( 1960 ) presented data to indicate that there is also a leucine-nicotinic acid relationship. Pèllagra has occurred in India among people subsisting on millet which, compared with rice, contains much more leucine but about the same amount of nicotinic acid. When pellagrins were placed on the millet diet excretion of $\mathrm{N}^{\prime}$-methylnicotinamide increased, but it returned to normal when the millet was replaced by rice. Similarly, daily doses of L-leucine increased the excretion of $\mathrm{N}^{\prime}$-methylnicotinamide of normal subjects and exaggerated symptoms of pellagra in pellagrins. Gopalan \& Srikantia (1960) suggested that in diets marginal in protein, the amino acid imbalance caused by a relative excess of leucine may lead to depletion of nicotinic acid in tissues. More recent work by the same group (Belavady, Srikantia \& Gopalan, 1963) indicates that the excretion of quinolinic acid is increased to a greater extent than that of $\mathrm{N}^{\prime}$-methylnicotinamide.

\section{Protein-vitamin A}

There have been conflicting reports on the relation between protein deficiency and absorption and utilization of vitamin $\mathrm{A}$ and carotene. Esh, Bhattacharya \& Som ( 1960$)$ and others reported that when there was insufficient protein or poorquality protein in the diet vitamin A storage was reduced. On the other hand, Murray (I96I) of our laboratory and others showed that rats were able to store ample amounts of vitamin $A$ on diets of poor-quality protein or even on a proteinfree diet. This finding has now been confirmed by Mathews \& Beaton ( 1963 ) using diets containing 0,4 and $20 \%$ casein protein.

Rechcigl, Berger, Loosli \& Williams (1962) assayed the livers and kidneys of rats with large stores of vitamin $\mathrm{A}$ that had been given diets varying in quantity and quality of protein. The highest vitamin A content was observed in livers and kidneys of rats fed on the protein-free diet. With increasing proportion of dietary protein there was a progressive decrease in the amount of vitamin $A$ in the liver and an increase in that in the kidneys. In rats ingesting an $18 \%$ casein diet, less vitamin $\mathrm{A}$ was found in the liver and more in the kidney than in slower-growing animals given $18 \%$ gluten or zein. The efficiency of vitamin A utilization, calculated after correction for maintenance, was decreased by protein of inferior quality but was not affected by the level of dietary protein. Differences in total vitamin A per liver were not as great as in the amount per unit weight of liver. Results reported by Mathews $\&$ Beaton (1963) are in general agreement with these findings and suggest that protein is closely concerned with vitamin A transport. 
From a practical aspect, the effect of protein deficiency on carotene absorption and utilization is probably more important since carotene is the chief source of vitamin A activity in those areas depending largely on plant protein. Friend, Heard, Platt, Stewart \& Turner (196r) showed that pigs on low-protein diets had lower liver stores of vitamin $A$ than animals on diets adequate in protein, which was considered to be due both to impaired conversion of carotenoids and to reduced absorption of vitamin $\mathrm{A}$ in the protein-deficient animals. The concentration in the serum was also reduced in animals fed on protein-deficient diets. Berger, Rechcigl, Loosli \& Williams (1962) reported that a nitrogen-free diet decreased, but did not prevent, carotene conversion and storage as vitamin A. The efficiency of carotene recovery as vitamin $A$ was affected by both quantity and quality of protein, and amino acid supplementation improved it. Mathews \& Beaton (1963) found that the liver and blood of rats given carotene contained less vitamin A when the diets were low in protein. In general the data suggest an interference with the absorption or conversion of carotene at low protein levels and may explain the low serum levels of vitamin A found in kwashiorkor. Arroyave, Wilson, Méndez, Béhar \& Scrimshaw (196I) found that treatment of kwashiorkor increased the serum levels of vitamin $A$ although the diets did not contain vitamin A or carotene. Whether this increase reflects the metabolic requirement on the high-protein diet or an increase in the vitamin A-carrying protein fraction in the serum was not clear, although the correlation of serum vitamin A and serum albumin (Friend et al. 196r) suggests the latter.

Protein depletion seems to interfere with the absorption and utilization of carotene, and to retard utilization of liver reserves of vitamin A. Its effect on absorption of vitamin $A$ is not clear. The problem is of considerable practical importance in areas where both protein and vitamin $\mathrm{A}$ are limiting.

\section{Protein-riboflavine}

It has been clearly established that animals and man on low protein intakes excrete relatively large amounts of riboflavine (Bro-Rasmussen, 1958). Czaczkes \& Guggenheim ( 1946 ) fed rats on diets containing casein to supply I I, 20 and $34 \%$ of the calories with graded amounts of riboflavine or without it. On the low-protein diet the riboflavine content of the organs was low, whatever the amount given, and excretion was relatively high. Apparently the rats could not retain and make use of riboflavine. On the high-protein diet more riboflavine was required to maintain tissue levels of riboflavine than on the normal $20 \%$ protein diet. The amount of riboflavine required was influenced in the same way by more fat in the diet, and the authors suggested that the effect of both protein and fat was to reduce intestinal synthesis. This theory was supported by other work with rats in which the riboflavine requirement did not increase with protein intake when sucrose was the source of carbohydrate or when dogs, which exhibit little intestinal synthesis, were the test animals (Bro-Rasmussen, 1958). It appears therefore that riboflavine requirement as measured by excretion in the urine and retention in tissues bears no constant relation to protein intake. When protein intake is below requirement there is difficulty in establishing retention of riboflavine. When protein intake is high it has no effect on riboflavine excretion except 23 (1) 3 
as it may interfere with intestinal synthesis and so produce an apparent increase in requirement.

Since riboflavine requirements vary with the protein intake, they can be accurately specified only for individuals in positive nitrogen balance. Normal daily variations in dietary protein probably do not influence the requirements. As men grow older they tend to go from positive to negative nitrogen balance and have lower riboflavine levels in their tissues. Since retention is poorer, increased intakes of riboflavine may be necessary to prevent deficiency signs.

\section{Fat-vitamin $E$}

Fat exerts an effect on the requirement for both water-soluble and fat-soluble vitamins. During the last few years there has been a great deal of emphasis on the effect of unsaturated fatty acids on hypercholesterolaemia and related conditions. There has been much less emphasis on the effects of these fats on vitamin E metabolism. Horwitt, Harvey, Century \& Witting (I96I) reviewed the relationship between these two factors and showed that dietary oils supplying a high proportion of peroxidizable lipids produced high creatine : creatinine ratios in rats unless the animals were given tocopherol. Rats given coconut oil or no fat did not require additional tocopherol because their creatine ratios did not increase. The incidence of encephalomalacia in chicks was proportional to the amount of stripped maize oil added to the diet when there was no tocopherol supplement. The incidence of the condition in all groups was reduced to nil with added tocopherol. In chicks, lipids of brain mitochondria were markedly influenced by the dietary oil, the content of $\mathrm{C}_{22}$ : 5 acids being much higher with a maize-oil than with a coconut-oil diet. In rats, chicks, monkeys and man blood levels of tocopherol were reduced and linoleic acid content of erythrocytes increased over a period of time by diets high in unsaturated fatty acids.

More recently Horwitt, Century \& Zeman ( 1963 ) pointed out that it is becoming increasingly apparent that, if the diet of a growing animal is reasonably low in polyunsaturated fats and if other lipid antioxidants are provided, the amounts of tocopherol needed during the early stages of life may be so small that none can be detected in the tissues. Or, stated in another way, the amount of tocopherol needed by an animal under these conditions is less than that found in experimental diets. Experiments on man indicate that the requirement varies from less than $5 \mathrm{mg}$ tocopherol to about $30 \mathrm{mg}$ daily. The lower quantity is found in diets containing animal fats and relatively low in unsaturated lipids, and $30 \mathrm{mg}$ is barely sufficient to reverse the peroxide haemolysis produced by prolonged ingestion of maize oil.

Factors that must be considered in evaluating tocopherol needs are (I) the polyunsaturated fatty acid and essential fatty acid contents of the diet, (2) composition of lipids in the body, (3) the specific pattern of fatty acid distribution in the organ or tissue, (4) time as it relates to consumption of a specific diet, and (5) the effect of other metabolic stresses which may alter the need for antioxidant protection.

Available data may be interpreted as indicating that excesses of linoleic acid in the tissues could be undesirable because of the large amount of tocopherol needed to 
prevent lipid peroxidation. Such data demonstrate the possible far-reaching effects of relatively simple dietary modifications, and the need for critical evaluation of such modifications.

\section{Carbohydrates}

Although not strictly a carbohydrate, the effect of sorbitol may be conveniently discussed under this heading. D-sorbitol can enhance the absorption of orally administered vitamin $B_{12}$ in man and animals and the absorption of iron by rats. Morgan \& Yudkin (1957) found that adding D-sorbitol to a diet deficient in thiamine brought about normal growth of rats. Okuda, Hsu \& Chow (1960) demonstrated that $D$-sorbitol added to a diet deficient in vitamin $B_{6}$ increased urinary excretion and liver concentrations of vitamin $B_{6}$ in adult rats and improved growth rate of weanling rats. On the other hand, after D-sorbitol had been included in the diet at a level of $10-20 \%$ for 8-12 weeks intestinal absorption of radioactive vitamin $B_{12}$ given orally was reduced. Furthermore, the addition of $\mathrm{D}$-sorbitol to a diet deficient in vitamin $\mathrm{B}_{12}$ did not improve the growth of weanling rats. 'These findings appeared to contradict earlier reports by the same group of increased absorption when vitamin $B_{12}$ was co-administered by mouth to normal rats and human subjects. The difference was explained on the basis of the difference in physical state of the vitamin $\mathrm{B}_{12}$ and sorbitol.

Peppler, Müller \& Cremer ( 1960 ) were unable to confirm the thiamine-sparing action of sorbitol in man. Challener \& Korst (I960) found with human subjects that sorbitol added to vitamin $B_{12}$ preparations did not increase absorption of labelled vitamin $\mathrm{B}_{12}$ with or without intrinsic factor. Such mixtures offered no treatment for pernicious anemia. Morgan \& Yudkin (1962) reviewed this whole field and concluded that there appear to be two types of sparing action involved. The first is represented by the limited sparing action on vitamin $\mathrm{B}_{12}$ and folic acid. The second is illustrated by experiments on rats and mice in which they may be made entirely independent of dietary sources of a variety of $\mathrm{B}$ vitamins. The data as a whole demonstrate that results may vary markedly, depending on experimental conditions.

\section{Minerals}

Minerals may influence the requirements for several vitamins and one of the most interesting interrelationships is that of selenium and vitamin $\mathrm{E}$, which has been discussed by Diplock, Edwin, Bunyan \& Green (1961) and many others. Another interrelationship involving a human health problem concerns the formation of urinary calculi largely composed of calcium oxalate. It has been established that the endogenous oxalate excretion of man, cats and rats is inversely related to the amount of pyridoxine in the diet (Gershoff \& Faragalla, 1959). Gershoff \& Andrus ( $196 \mathrm{I})$ found that high dietary levels of magnesium $(400 \mathrm{mg} / \mathrm{r} 00 \mathrm{~g}$ diet) provided marked protection against oxalate deposition in vitamin $\mathrm{B}_{6}$-deficient rats given diets supplemented with glycine, a precursor of endogenous oxalate. Considerably more oxalate was excreted by vitamin $B_{6}$-deficient rats than by their controls at all levels of magnesium intake. The authors suggest that the increased dietary magnesium may 
increase the solubility of oxalate in the urine of vitamin $B_{6}$-deficient rats. Vitamin $\mathrm{B}_{6}$-deficient rats also excrete markedly less citrate. The low citrate excretion was prevented by high dietary levels of magnesium as well as by the addition of pyridoxine. Since it was shown that citrate is largely responsible for increasing the solubility of calcium oxalate it seems possible that increased urinary calculi in pyridoxine deficiency may be due to a decrease in urinary citrate levels as well as an increase in oxalate levels. The effect of large amounts of magnesium in reducing renal calculi appears to be due to the increased excretion of citrate. Additional data showed that normal human subjects excreted more citric acid than patients with kidney stones.

As Gershoff \& Andrus (I96I) point out, until recently nutritionists have been concerned almost entirely with problems of undernutrition rather than of overnutrition. Although in populations receiving diets high in dairy products there has been no marked increase in diseases associated with high-calcium diets, formation of kidney stones has been related in some patients to excessive milk consumption. The results of studies by the same authors in which the calcium content of the diet was varied indicate that, under circumstances favourable to the production of calcium oxalate, low-calcium diets may be advisable.

Another example of the effect of a high intake of a nutrient is that of iron on vitamin $\mathrm{B}_{12}$ reported by Booth \& Spray ( 1962 ). They treated gastrectomized rats with iron by intramuscular injection and found the treated animals had less vitamin $B_{12}$ in liver and serum than untreated operated animals. The animals were investigated for Io-20 weeks. It was suggested that artificial maintenance of high levels of tissue iron permitted increased haematopoiesis with resulting loss of vitamin $B_{12}$ from serum and liver. The data suggest that high levels of nutrients may not be best under all conditions.

\section{Vitamins}

In studies of the effect of acute vitamin deficiency, experimental animals are usually given a diet complete in all known vitamins except the one under test. It is assumed that the vitamins provided in the diet will meet the so-called normal requirements on the premise that the deficient animals will have a normal dietary intake with no impairment of absorption. As Ranke, Ranke \& Chow (I960) pointed out, neither assumption may be true since deficient animals usually consume lesser amounts of the experimental diet, and a deficiency of one vitamin may impair the absorption or utilization, or both, of another. They found that vitamin $\mathrm{B}_{6}$-deficient animals on a diet low in vitamin $B_{6}$ became deficient in vitamin $B_{12}$ although the diet contained unusually large amounts of vitamin $B_{12}$. Furthermore, animals receiving excessive amounts of vitamin $B_{6}$ exhibited a marked decrease in serum and liver levels of vitamin $B_{12}$.

As demonstrated earlier by Morrison \& Sarett (1959a), however, these effects do not apply to other $B$ vitamins. They gave weanling rats diets, otherwise adequate, containing low, adequate or high levels of one B vitamin in combination with low, adequate or high levels of a second B vitamin. A deficiency of thiamine, riboflavine, 
pyridoxine or pantothenate significantly reduced weight gain and efficiency of food utilization. Those animals deficient in thiamine and another vitamin grew at rates similar to those deficient in thiamine alone. High levels of thiamine had no influence on the weight gain or efficiency of food utilization of rats deficient in pyridoxine, pantothenate or riboflavine. Similarly, no effects of high levels of pyridoxine, pantothenate or riboflavine were observed on the severity of thiamine deficiency. A study was also made of the effects of administration of excess thiamine, riboflavine, pyridoxine or pantothenate to animals deficient in the other three $B$ vitamins. No adverse effect of thiamine, pyridoxine or pantothenate was noted, but excess riboflavine depressed gain and food conversion efficiency and increased mortality of rats deficient in the other vitamins. In a second series of experiments, the same authors (Morrison \& Sarett, 1959b) reported that excess thiamine or pyridoxine or both had no effect on weight gain or reproductive performance of animals after parturition and lactation.

There are metabolic interrelationships between $B$ vitamins in several animal species. Some of those between vitamin $\mathrm{B}_{12}$ and pantothenic acid have been discussed by Aiyar \& Sreenivasan ( 1961 ). Hsu ( 1963 ) summarized work showing that absorption of vitamin $B_{12}$ was reduced in rats with vitamin $B_{6}$ deficiency. Since labelled vitamin $B_{12}$ introduced into the intestinal loops of vitamin $B_{6}$-deficient and treated animals was absorbed to the same extent, the integrity of the gastro-intestinal tract for vitamin $B_{12}$ absorption seemed to be maintained. The effect of the vitamin $B_{6}$ deficiency seemed primarily to be a reduction in both the secretion of gastric juice and the production of vitamin $\mathrm{B}_{12}$-binding substances.

On the other hand, since folic acid deficiency increased the absorption of vitamin $B_{12}$ and a deficiency of several other vitamins, e.g. thiamine, riboflavine, pantothenic acid, nicotinic acid, biotin and choline had no effect, the author postulated that the effect of each vitamin deficiency was a specific one.

\section{Summary}

It appears that vitamin requirements are not absolute in nature but are subject to considerable variation depending on the amounts of other nutrients present in the diet. The effects of many nutrients are not clear cut and seem to depend to a certain extent on experimental conditions. Under conditions of an adequate intake of a 'normal' diet, the factors described are probably not of great importance. When the diet has been modified to a significant extent, however, or when it is borderline in nutrient content, it may be expected that requirements will vary markedly. Excessive intakes of individual nutrients may be almost as important as low intakes in influencing requirements for vitamins. Evidence is accumulating that so-called optimum intakes of nutrients are not maximum intakes but, as Hegsted (I96I) states, 'are somewhere in between too little and too much'.

\section{REFERENCES}

Aiyar, A. S. \& Sreenivasan, A. (1961). F. Nutr. 75, 235.

Arroyave, G., Wilson, D., Méndez, J., Béhar, M. \& Scrimshaw, N. S. (1961). Amer. F. clin. Nutr. 9, 180. Belavady, B., Srikantia, S. G. \& Gopalan, C. (1963). Biochem. \%. 87, 652. 
Berger, S., Rechcigl, M. Jr., Loosli, J. K. \& Williams, H. H. (1962). F. Nutr. 77, I74.

Booth, M. A. \& Spray, G. H. (1962). Brit. F. Haemat. 8, I ro.

Bro-Rasmussen, F. (1958). Nutr. Abstr. Rev. 28, 369.

Challener, W. A. \& Korst, D. R. (1960). Amer. F. med. Sci. 240, 226.

Czaczkes, J. W. \& Guggenheim, K. (1946). F. biol. Chem. 162, 267.

Diplock, A. T., Edwin, E. E., Bunyan, J. \& Green, J. (196I). Brit. F. Nutr. 15, 425.

Esh, G. C., Bhattacharya, S. \& Som, J. M. (1960). Ann. Biochem. 20, 15.

Friend, C. J., Heard, C. R. C., Platt, B. S., Stewart, R. J. C. \& Turner, M. R. (196r). Brit. J. Nutr. I5, 231.

Gershoff, S. N. \& Andrus, S. B. (1961). F. Nutr. 73, 308.

Gershoff, S. N. \& Faragalla, F. F. (1959). F. biol. Chem. 234, 239 I.

Gopalan, C. \& Srikantia, S. G. (I960). Lancet, i, 954.

Hegsted, D. M. (1 96 r). Amer. F. clin. Nutr. 9, 548.

Horwitt, M. K., Century, B. \& Zeman, A. A. (1963). Amer. F. clin. Nutr. r2, 99

Horwitt, M. K., Harvey, C. C., Century, B. \& Witting, L. A. (1961). F. Amer. diet. Ass. 38, 231.

Hsu, J. M. (1963). Amer. F. clin. Nutr. 12, 170.

Mathews, J. \& Beaton, G. H. (1963). Canad. F. Biochem. 4I, 543 .

Morgan, T. B. \& Yudkin, J. (1957). Nature, Lond., 180, 543.

Morgan, T. B. \& Yudkin, J. (1962). Vitam. \& Horm. 20, 39.

Morrison, A. B. \& Sarett, H. P. (I959a). F. Nutr, 68, 473.

Morrison, A. B. \& Sarett, H. P. (1959b). F. Nutr. 69, I I I.

Murray, T. K. (I96r). Canad. F. Biochem. 39, ro99.

Okuda, K., Hsu, J. M. \& Chow, B. F. (1960). F. Nutr. 72, 99.

Peppler, E., Müller, B. \& Cremer, H. D. (1960). F. Nutr. 71, 9 I.

Ranke, B., Ranke, E. \& Chow, B. F. (1960). F. Nutr. 7I, 4 II.

Rechcigl, M. Jr., Berger, S., Loosli, J. K. \& Williams, H. H. (I962). F. Nutr. 76, 435.

\section{Metabolic interrelationships in the utilization of trace elements}

\section{By C. F. Mills, Rowett Research Institute, Bucksburn, Aberdeen}

The behaviour of the trace elements in biological systems is mostly a reflection of the strong affinity of cellular components for these elements. This behaviour can be modified by changes in the environment of the cell which influence the supply of a particular element available to participate in cellular reactions, by changes which modify cellular components in such a manner that their affinity for the element is increased or decreased, or by changes in the intra- or extra-cellular concentration of elements which compete for a specific binding site. Although in this review we are concerned with nutritional changes that may modify trace-element metabolism in the intact animal we are, in effect, dealing with these reactions. With this in mind I have selected examples of recent advances in knowledge of the influence of the nature of the diet on processes such as the liberation of trace elements from food material, the storage of these elements in the tissues, their incorporation into their functional units in the cell and finally their excretion.

\section{The influence of the type of dietary protein source on trace-element metabolism}

The nature and quantity of the protein source in a diet can have a significant effect upon the utilization of trace elements from that diet. For example, Morrison \& Sarett (1958) found that the zinc requirement of the chick is apparently increased when isolated soya-bean protein is used instead of casein or gelatin as a protein source in synthetic diets. This observation was fully confirmed by other workers, and later 